\title{
Migration and Magnitude of Psychological Distress
}

\author{
Seema Sharma and Sushma Jaswal \\ Department of Human Development and Sociology, College of Home Science, \\ Punjab Agricultural University, Ludhiana 141 004, Punjab, India
}

KEYWORDS Psychological distress; migrant; local; labourer

\begin{abstract}
This study was conducted to assess the magnitude of psychological distress among migrant labourers. The study is based upon a sample of 240 labourers (18 years and above in age) drawn in equal numbers from four randomly selected villages and four cycle manufacturing units of Ludhiana district. The results revealed that migrant labourers had more psychological distress than the local labourers. The magnitude of psychological distress (inadequacy, anxiety, anger) was found to be significantly more in industrial sector and among migrants who had spent one year or less in Punjab.
\end{abstract}

\section{INTRODUCTION}

Migration is the process of social change whereby an individual moves from one cultural settings to another for the purpose of settling down either permanently or for a prolonged period. Such a shift can be for any number of reasons, commonly economic, political or educational betterment. The process is inevitably stressful and stress can lead to mental illness.

It has been noticed that during the last decade the rate of such migration into Punjab is on increase. In the wake of green revolution in Punjab and widespread adoption of wheat-paddy rotation, which is quiet labour intensive, the farmers of the state have become largely dependent on migratory labour. The ratio of migrant labour against local labour is approximately 80:20 in case of industrial sector and 70:30 in respect of agriculture sector (Gill, 2002)

The stress associated with relocation is analysed in the World Bank's study in terms of three categories. Psychological stress includes the "grieving for a lost home syndrome", "anxiety for the future" and "feelings of impotence" associated with one's inability to protect one's home and community from disruption (United Nations, 1985).

\section{METHODOLOGY}

The present study was undertaken in

Address correspondence to: Seema Sharma,

Telephone: 2409476 ,

E-mail: vk_Sharma65@yahoo.co.uk
Ludhiana district to examine the magnitude of psychological distress among migrant labourers in Punjab. The sample for the present study was drawn from cycle manufacturing units and villages of the Ludhiana district. The sample consisting of 240 labourers above 18 years of age was drawn in equal numbers from two enterprises that is cycle manufacturing units $(n=120)$ and agriculture $(n=120)$. Four cycle manufacturing units were selected randomly from a list of cycle manufacturing units employing at least 150 labourers in their enterprise. In case of agricultural enterprise, four were selected randomly from two randomly selected blocks of Ludhiana district. The sample for the present study $(n=240)$ included 40 local labourers and 80 migrant labourers in each of the selected enterprises. Further, two groups of migrant labourers were selected purposively on the basis of length of time spent in Punjab after migration. One group of migrant labour included those $(\mathrm{n}=$ 40) who were here for more than one year while the second group $(n=40)$ had spent less than or equal to one year in either of the two enterprises.

The Cornell Medical Index Health Questionnaire developed by Wig, Parshad and Verma (1983) was administered to assess the magnitude of psychological distress among labourers.

\section{Levels of Psychological Distress}

Table 1 depict the distribution of the laboureres according to the level of psychological distress. It is clear from the table that in agricultural sector, there were half of the local labourers who 
suffered from average level of psychological distress while a significantly low number $(15 \%)$ of them were suffering from high level of psychological distress. In case of migrant labourers with one year or less stay as high as 70 per cent of them were suffering from average level of psychological distress. This proportion was significantly higher than those suffering from low level of psychological distress. In case of migrant labourers with one year or less stay the percentage of labourers $(55 \%)$ with average level of psychological distress was significantly higher than those who suffered from high level of psychological distress (10\%).

In industrial sector, 42.50 per cent of local labourers suffered from low level of psychological distress and the remaining 57.50 per cent showed average level of psychological distress. Statistically there was no significant difference in the percentages. In case of migrant labourers with one year or less stay and with more than one year of stay significantly higher proportions were found to be suffering from average level of psychological distress. There was no significant difference in percentage for various levels of psychological distress between different categories of industrial labourers. However, there were significant differences in proportions for various levels of psychological distress within each and every category of labourers being considered by the present study.

\section{Patterns of Psychological Distress}

The pattern of psychological distress observed for agricultural labourers (Table 2) did not vary across local, migrant labour with one year or less stay' or more than one year stay'.

Table 1: Levels of psychological distress among agricultural and industrial labourers.

\begin{tabular}{|c|c|c|c|c|c|c|c|c|c|}
\hline \multirow[t]{3}{*}{ S. No. } & \multirow[t]{3}{*}{ Respondents Category } & \multicolumn{8}{|c|}{ Levels of psychological distress } \\
\hline & & \multicolumn{2}{|c|}{ Low } & \multicolumn{2}{|c|}{ Average } & \multicolumn{2}{|c|}{ High } & \multicolumn{2}{|c|}{ Total } \\
\hline & & $n$ & $(\%)$ & $n$ & $(\%)$ & $n$ & $(\%)$ & $n$ & $(\%)$ \\
\hline \multicolumn{10}{|c|}{ A. Agricultural } \\
\hline 1 & Local & 14 & $(35)$ & 20 & $(50)^{* *}$ & 6 & (15) & 40 & $(100)$ \\
\hline 2 & Migrant & & & & & & & & \\
\hline i) & $\leq 1$ year stay & 12 & (30) & 28 & $(70) * * *$ & 0 & (0) & 40 & $(100)$ \\
\hline \multirow[t]{2}{*}{ ii) } & $>1$ year stay & 14 & (35) & 22 & $(55)^{* *}$ & 4 & (10) & 40 & $(100)$ \\
\hline & Total & 40 & (33.33) & 70 & $(58.33)$ & 10 & $(8.34)$ & 120 & $(100)$ \\
\hline \multicolumn{10}{|c|}{ B. Industrial } \\
\hline 1 & Local & 17 & $(42.50)$ & 23 & $(57.50)$ & 0 & $(0)$ & 40 & $(100)$ \\
\hline 2 & Migrant & & & & & & & & \\
\hline i) & $\leq 1$ year stay & 13 & $(32.50)$ & 27 & $(67.50)^{* * *}$ & 0 & (0) & 40 & $(100)$ \\
\hline ii) & $>1$ year stay & 15 & $(37.50)$ & 25 & $(62.50) * *$ & 0 & (0) & 40 & $(100)$ \\
\hline \multicolumn{2}{|c|}{ Total } & 45 & $(37.50)$ & 75 & $(62.50)$ & 0 & (0) & 120 & $(100)$ \\
\hline
\end{tabular}

** Significant at $5 \%$ level

*** Significant at $1 \%$ level

Levels of significance of difference between proportions (z-test)

Table 2: Extent of psychological distress (expressed as percent scores for various distress parameters) among agricultural and industrial labourers.

\begin{tabular}{|c|c|c|c|c|c|c|c|}
\hline \multirow{2}{*}{$\begin{array}{l}\text { Labourers } \\
\text { group }\end{array}$} & \multirow{2}{*}{$\begin{array}{l}\text { Agricultural/ } \\
\text { Industrial } \\
\text { labourers }\end{array}$} & \multicolumn{6}{|c|}{ Dimensions of psychological distress } \\
\hline & & Inadequacy & Tension & Anger $s$ & Sensitivity & Depression & Anxiety \\
\hline \multirow[t]{3}{*}{ Local } & Agricultural & 36.08 & 22.56 & 19.22 & 17.17 & 15.83 & 13.11 \\
\hline & Industrial & 38.83 & 23.11 & 24.44 & 15.83 & 13.83 & 14.22 \\
\hline & (Agril.-Indust) more/less & -2.75 & -0.55 & -5.22 & 1.34 & 2 & -1.11 \\
\hline \multirow{3}{*}{$\leq 1$ year stay } & Agricultural & 45 & 30.33 & 28.33 & 26.33 & 25.5 & 24.44 \\
\hline & Industrial & 54.14 & 28.67 & 29.33 & 23.83 & 23 & 27.78 \\
\hline & (Agril.-Indust) more/less & -9.14 & 1.66 & -1 & 2.5 & 2.5 & -3.34 \\
\hline \multirow[t]{5}{*}{$>1$ year stay } & Agricultural & 35.42 & 26.78 & 24.22 & 19.33 & 17.5 & 17.78 \\
\hline & Industrial & 41.5 & 25.33 & 26.44 & 18.67 & 15.83 & 20.56 \\
\hline & (Agril.-Indust) more/less & -6.08 & 1.45 & -2.22 & 0.66 & 1.67 & -2.78 \\
\hline & F-Ratio & 6.22 & 5.68 & 10.34 & 1.41 & 3.07 & 1.32 \\
\hline & $\mathrm{CD} 5 \%$ & 0.6522 & 0.247 & 0.3904 & $4 \quad \mathrm{NS}$ & 0.2408 & NS \\
\hline
\end{tabular}


The sequence of psychological distress dimensions were same for all these groups when arranged in descending order as per mean per cent scores. This pattern included the following psychological distress parameters as inadequacy, tension, anger, sensitivity, depression, anxiety. The only variation observed was that the anxiety was recorded first followed by depression among migrant labour with more than one year stay. The pattern of psychological distress observed for industrial labour was partly different among local labourers. Inadequacy, anger, tension occurred in the descending order among all the three industrial labour groups. Among local industrial labour the sequence was sensitivity, anxiety and depression. On the other hand the descending sequence of psychological distress dimensions was the same for migrant labourers irrespective of their stay, it included in sequence as inadequacy, anger, tension , anxiety, sensitivity and depression. The comparison of these sequence patterns of psychological distress does indicate that inadequacy, tension and anger are important psychological dimension contributing to the distress observed among labourers of all categories.

\section{Magnitude and Extent of Psychological Distress}

The following account discusses all the six psychological distress dimensions separately to compare various groups of agricultural and industrial labourers.

a) Inadequacy: Mean per cent scores for inadequacy were highest among all three groups of labourers irrespective of their working in the agricultural and industrial sector. It is evident from table 2 that mean per cent scores for inadequacy were found to be higher for all the three groups of industrial labourers namely local (38.83), migrants with less than one year stay' (54.14) and with more than one year stay' (41.50). The magnitude of difference among local agricultural and industrial labourers for inadequacy dimension of psychological distress was 2.75 per cent (in favour of industrial), whereas corresponding difference for migrant labourer with one year or less stay was 9.14 per cent (in favour of industry) and with more than one year stay', it was 6.08 per cent (in favour of industry). These observations clearly indicate that inadequacy causes psychological distress more in the industrial labourers than agricultural labourers, but it is much more pronounced among migrant labourers. It could be inferred that inadequacy seems to be a function of duration of stay. The mean per cent scores tend to decrease with increased in duration of stay. Statistically all the groups differed significantly from each other $(\mathrm{F}-$ ratio $=6.22, \mathrm{CD} 5 \%=0.6522)$

b)Tension: The extent of tension was higher in agricultural labourers in all the categories except among local labourers where a slightly inverse trend could be seen. The extent of tension among agricultural labourers was 22.56 per cent in local labourers, 30.33 per cent in migrant labourer with one year or less stay' and 26.78 per cent in migrant with more than one year stay. The magnitude of difference in extent for local labourers for tension dimension of psychological distress was $(0.55 \%)$ more in industrial labourers, while the same for migrant labourers one year or less stay' was 1.66 per cent more in agricultural sector. The analysis shows that the tension causes higher level of distress in the agricultural sector among migrant labourers while the same was higher in industrial sector among local labourers. It can also be inferred that tension seems to be a function of duration of stay as the extent of tension reveals an inverse relationship with the duration of stay in Punjab. Statistical comparison of different categories of labourers showed that they differ significantly from each other $($ F-ratio $=5.68)$.

c) Anger: It is obvious from the table 2 that extent of anger was more in industrial sector as compared to the agricultural sector irrespective of the categories of labourers. There were statistically significant differences among all groups of labourers. The extent of anger in industrial sector came to be 24.44, 29.33 and 26.44 per cent among local, migrant with one year or less stay' and migrant with more than one year stay' respectively. The gap between the magnitude of difference in the extent of anger in agricultural and industrial sector did not depict any definite trend in relation to the categories of labourers yet the extent of anger was inversely related with the duration of stay i.e. more the duration of stay, lower is the extent of anger. This analysis clearly showed that psychological distress due to anger dimension was more in industrial sector as compared to that in the agricultural sector.

d) Sensitivity: No statistically significant differences could be observed between all groups 
of labourers for psychological distress caused by sensitivity. The mean per cent of extent of distress due to sensitivity was more in agricultural sector as compared to that in industrial sector among all the categories of labourers.

The analysis highlighted two things, one, the psychological distress due to sensitivity was higher in agricultural sector as compared to that in industrial sector and the second, the extent of sensitivity distress decreased with duration of stay in Punjab. It is also revealed by the study that the psychological distress due to sensitivity was less among local labourers as compared to the migrant ones.

e) Depression: The extent of depression was found to be higher in agricultural sector as compared to the industrial sector. The extent of depression in industrial sector was recorded to be 13.83 per cent among local labourers, 23.00 per cent among migrant labourers with one year or less stay' and 15.83 per cent among migrant labourers with more than one year stay'.

The extent of depression was more in agricultural sector than industrial sector by 2.00 per cent among local labourers, 2.50 per cent among migrant labourers with one year or less stay' and 1.67 per cent among migrant labourers with more than one year stay'. It is further revealed that the distress due to depression was inversely related with the duration of stay. The extent of depression was also found to be more among migrant labourers as compared to the local ones as found by Nazroo (1997) that Indian and Pakistan migrants were more likely to suffer from depression, anxiety and suicidal thoughts. Statistical comparison of these groups showed that these are significantly different from each other $(\mathrm{F}$-ratio $=3.07)$.

f) Anxiety: The analysis shows that the extent of anxiety was more in industrial sector as compared to the agricultural sector among all the categories of labourers under study. The extent of anxiety was 13.11 and 14.22 per cent among local labourers in agricultural and industrial sectors. The same was found to be 24.44 and 27.78 per cent among migrant labourers with one year or less stay' in agricultural and industrial sector respectively. The corresponding figures among migrant labourers with more than one year stay were 17.78 and 20.56 per cent.

The difference in the extent of anxiety was much glaring in migrant labourers as compared to local labourers as Dalgard (1998) also reported that the use of antianxiety medicines was more prevalent among immigrants as compared to ethnic Norwegians. No statistically significant differences could be observed between all groups of labourers for psychological distress caused by anxiety.

\section{CONCLUSIONS}

It could thus be concluded from the present study that psychological distress was more in industrial sector and in migrant labourers as majority of studies on psychological adaptation among young immigrants have dwelt on negative outcomes such as anger, tension, depression and psychosomatic symptoms (Aronowitz, 1984; Rogler et al., 1991; Mirsky, 1997). Furnham and Bochner (1986) also found a positive relationship between migration and psychological disturbance. There is often a particular sense of stress that occurs during acculturation such as lowered mental health status (especially confusion, anxiety, depression) feeling of marginality and alienation, heightened psychosomatic symptom level and identity confusion.

Secondly psychological distress showed an inverse relationship with duration of stay as migrants may experience a period of grief after migration but may gradually recover from it and eventually adjust to the conditions of their new environment as per theories of social isolation and cultural shock that "the shorter the immigration period, the greater the shock," but as the migrants become acculturated, the intensity towards the development of illness will be gradually reduced (Kuo, 1976). Gupta (1988) also reported that the problem of adjustment is definitely dependent upon the duration of stay of immigrants. A study of greater Bombay (Zachariah, 1968) also shared the same views as longer the exposure of the immigrants to the city life, the greater is the resemblance to city born persons and hence more adjustments.

\section{REFERENCES}

Aronowitz, M. 1984. "The social and emotional adjustment of immigrant children: a review of literature." International Migration Review, 18: 2357.

Dalgard, O.S., I. Sandanger, T. Sorensen and G. Ingebrigsten. 1998. "Mental health among immigrants in OSCLO, Norway." Soc Psychi, 20: $107-12$. 
Furnham, A. and S. Bochner. 1986. Culture Shock: Psychological Reactions to Unfamiliar Environment. pp 104-10. New York: Methuen.

Gill, P.P.S. 2002. "Migrants Vs Local labour.” The Tribune, 3 Sept.

Gupta, A.K. 1988. "Socological Implications of rural to rural migration." Soc. Bul., 37: 113-14.

Kuo, W. 1976. "Theories of migration and mental health : An empirical testing on Chinese American." Social Science Medicine, 10: 297-306

Mirsky, J. 1997. "Psychological distress among immigrant adolescents: Culture-specific factors in the case of immigrants from the former Soviet Union." International Journal of Psychology, 32: $221-30$
Nazroo, J. 1997. Ethnicity and Mental Health. pp 21016. London: PSI.

Rogler, L.H., D. S. Cartes and R. G. Malgady. 1991. "Acclamation and mental health status among Hispanics: Convergence and new directions for research." American Psychologists, 46: 585-97

United Nations, 1985. "The abuse of indigenous people land rights and national legislation." The Fourth World Documentation Project. Geneva, 29 July-2Aug.

Wig, N.N., D. Pershad and S. K.Verma. 1983. C.M.I. Health Questionnaire. Agra: Psychological Corporation.

Zachariah KC 1968. Migrants in Greater Bombay. pp 10-16. Bombay: Asia Publishing House. 